\title{
Degenerative Cervical Myelopathy: Pathophysiology and Current Treatment Strategies
}

\author{
Sung Hoon Choi, Chang-Nam Kang \\ Department of Orthopaedic Surgery, Hanyang University College of Medicine, Seoul, Korea
}

Chronic compression or ischemia of the spinal cord in the cervical spine causes a clinical syndrome known as cervical myelopathy. Recently, a new term "degenerative cervical myelopathy (DCM)" was introduced. DCM encompasses spondylosis, intervertebral disk herniation, facet arthrosis, ligamentous hypertrophy, calcification, and ossification. The pathophysiology of DCM includes structural and functional abnormalities of the spinal cord caused by static and dynamic factors. In nonoperative patients, cervical myelopathy has a poor prognosis. Surgical treatments, such as anterior or posterior decompression accompanying arthrodesis, arthroplasty, or laminoplasty, should be considered for patients with chronic progressive cervical myelopathy. Surgical decompression can prevent the progression of myelopathy and improve the neurologic status, functional outcomes, and quality of life, irrespective of differences in medical systems and sociocultural determinants of health. The anterior surgical approach to the cervical spine has the advantage of removing or floating the intervertebral disk, osteophytes, and ossification of the posterior longitudinal ligament that compress the spinal cord directly. The posterior surgical approach to the cervical spine is mainly used for multisegment spinal cord compression in patients with cervical lordosis. In this review article, we addressed the pathophysiology, clinical manifestations, differential diagnosis, and treatment options for DCM.

Keywords: Spinal cord; Myelopathy; Cervical spine; Decompression; Surgery

\section{Introduction}

Chronic compression or ischemia of the spinal cord in the cervical spine causes a clinical syndrome known as cervical myelopathy, which involves spinal cord dysfunction. Cervical myelopathy is a common pathology that requires surgical treatment in individuals aged over 55 years [1]. Depending on the location and severity of spinal cord dysfunction, various signs and symptoms of myelopathy can appear, ranging from subtle symptoms, such as reduced balance and dexterity of the extremities, to severe sequelae of paralysis and urinary incontinence. Unlike an acute spinal cord injury, nontraumatic and degenerative spondylosis of the cervical spine is the commonest cause of spinal cord impairment in the elderly patients. Nouri et al. [2] proposed a new term, degenerative cervical myelopathy (DCM), which encompasses ligamentous hypertrophy, calcification, or ossification (conditions which cause progressive spinal cord compression and neurologic dysfunction with advancing age) in addition to spondylosis, intervertebral disk herniation, and facet arthrosis.

Surgical treatments, such as anterior or posterior de-

Received Sep 19, 2020; Accepted Sep 20, 2020

Corresponding author: Chang-Nam Kang

Department of Orthopaedic Surgery, Hanyang University College of Medicine, 222-1 Wangsimni-ro, Seongdong-gu, Seoul 04763, Korea

Tel: +82-2-2290-8485, Fax: +82-2-2299-3774, E-mail: cnkang65@hanyang.ac.kr 
compression accompanying arthrodesis, arthroplasty, or laminoplasty, should be considered for patients with chronic progressive cervical myelopathy who are nonresponsive to conservative treatment. The goal of surgical treatment is to relieve the mechanical compression of the spinal cord and extend the spinal canal. The selection of the appropriate surgical treatment should be individualized according to levels of involved pathologies, clinical manifestations, and radiologic factors. In this review article, we aimed to address the pathophysiology, clinical manifestations, differential diagnosis, and treatment options for DCM.

\section{Pathophysiology}

The pathophysiology of DCM includes structural and functional abnormalities in the spinal cord that are caused by static factors, such as congenital spinal canal stenosis and cervical spondylosis, and dynamic factors, such as microscopic repetitive spinal cord damage caused by cervical instability. Chronic compression of the spinal cord induces direct damage to neurons and glial cells and secondary ischemic cascade, excitotoxicity, and apoptosis $[1,3]$. Many authors have reported that the congenital or developmental cervical spinal stenosis is associated with the development of cervical myelopathy [4-6]. At the midcervical region, the normal sagittal diameter of the spinal canal has been reported to be about 17-18 $\mathrm{mm}$ [4]. It has been observed that patients with a sagittal diameter of $<13$ $\mathrm{mm}$ have a high risk of developing myelopathy [5]. It is well known that absolute spinal stenosis is possible when the sagittal diameter is $<10 \mathrm{~mm}$ [4-6]. The measurement of the sagittal diameter of the spinal canal can provide inaccurate results due to differences in values of radiographic magnification. Therefore, the measurement of the ratio of the sagittal diameter of the spinal canal to that of the vertebral body will provide accurate results to assess the severity of spinal canal stenosis [7]. Pavlov et al. [7] reported that the risk of developing cervical myelopathy was high when the abovementioned ratio was $<0.82$.

Cervical spondylosis is the most common static pathology that results in spinal cord compression. It is observed in $55 \%$ of patients who have cervical myelopathy [8]. A decrease in disk height induces narrowing of the spinal canal by varying degrees of the herniated intervertebral disk. Additionally, microinstability induces osteophyte formation at the vertebral end plates in the involved segments. Furthermore, hypertrophy in the facet joints accompanying intervertebral disk herniation leads to progressive spinal stenosis, which eventually results in cervical myelopathy [9]. Other static factors, such as facet cyst, ossification of the posterior longitudinal ligament (OPLL), and ossification or calcification of the ligamentum flavum, may further diminish the cross-sectional area of the spinal canal, which may aggravate cervical myelopathy.

Dynamic factors of the cervical spine, such as buckling of the ligamentum flavum, may also result in myelopathy. Cervical myelopathy can occur when the dynamic sagittal diameter is $<11 \mathrm{~mm}$ during extreme flexion or extension [10]. Cervical spine instability is defined as a translation of $>3.5 \mathrm{~mm}$ and an angulation of $>11^{\circ}$ in flexion-extension views of a dynamic radiograph. It affects the narrowing of the spinal canal [11]. In addition to mechanical or dynamic compression, increased strain or shear forces induce extensive or localized axonal damage to the spinal cord [12]. During physiologic flexion of the cervical spine, axial strain and stretching of the spinal cord can increase due to the elongation of the spinal canal [12]. Progressive cervical kyphosis can exacerbate cervical myelopathy due to increased intramedullary pressure by compressing the anterior spinal cord and increasing the tension in the spinal cord [13]. Shi and Pryor [14] reported that spinal cord elongation increased the temporary membrane permeability, causing a transient electrolyte imbalance and conduction loss in myelinated axons. Moreover, irreversible conduction loss resulted in more severe anatomical membrane damage as the spinal cord was stretched through an in vitro stretch model [14].

Many authors have demonstrated that ischemia is a major underlying pathologic condition that contributes to the aggravation of cervical myelopathy $[15,16]$. Karadimas et al. [15] reported that anterior cord compression inhibits perfusion of the anterior sulcus arteries through the transverse arterioles, whereas, posterior cord compression reduces central gray matter perfusion through intramedullary branches. Oligodendrocyte, a well-known cell type that is hypersensitive to an ischemic injury, is primarily responsible for insulating axons with myelin sheaths. However, oligodendrocytes may undergo apoptosis after an acute traumatic injury or chronic ischemic injury [16]. The ischemic condition initiates a biochemical cascade of increased concentrations of extracellular glutamate and the related cation-mediated cell damage, which results in apoptotic cell death [17]. The corticospinal tract is com- 
monly affected by an ischemic injury, which is associated with the clinical presentation of DCM $[15,18]$.

Recently, an apoptosis theory was introduced that accounted for active cell death after a traumatic or ischemic injury to the spinal cord [19]. Apoptosis after an acute spinal cord injury is considered to cause secondary degeneration in the lesions involved and chronic demyelination in regions far from the lesions [20]. Furthermore, ischemia and decreased blood flow to the spinal cord due to cervical spinal stenosis are important initiators of DCM. Oligodendrocyte apoptosis in an ischemic injury precedes axonal degeneration in myelopathy $[15,19]$. The early apoptotic loss of oligodendrocytes can predispose the patients with chronic cervical spinal cord compression to irreversible and extensive neurologic deficits [21].

\section{Clinical Manifestation}

The clinical symptoms of DCM have a very diverse spectrum and usually appear after the age of 40 years when spondylosis progresses. Men are more commonly affected with DCM compared with women (3:2) [22]. An insidious onset with global and nondermatomal paresthesia of the upper extremities and loss of hand dexterity are typical manifestations of DCM. Some elderly patients may complain of acute onset of symptoms after a hyperexten-

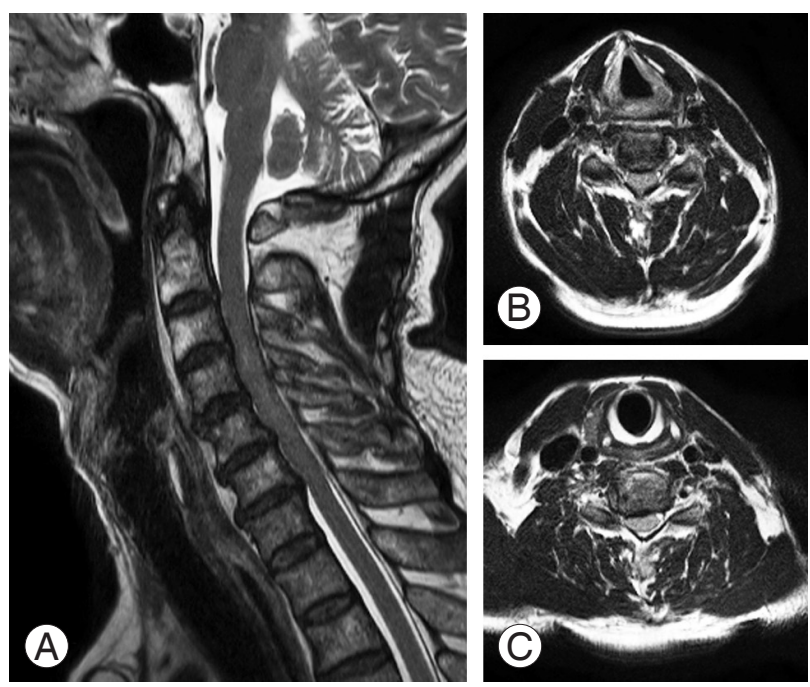

Fig. 1. A 64-year-old man visits the hospital with loss of dexterity in both hands, which rapidly worsens after hyperextension of the neck. (A) On the $\mathrm{MRI}$ sagittal plane, the diameter of the canal is narrowed due to congenital stenosis. (B) MRI axial plane shows a spinal canal diameter of $8.9 \mathrm{~mm}$ and the Pavlov ratio is 0.47 at C3-4 level. (C) The spinal canal diameter is $9.2 \mathrm{~mm}$ and the Pavlov ratio is reduced to 0.48 at $\mathrm{C5}-6$ level. MRI, magnetic resonance imaging. sion neck injury (Fig. 1). However, some patients may not experience pain or neurologic dysfunction, despite considerable spinal cord compression. The symptoms and signs of DCM depend on the severity of compression and levels of spinal cord and nerve root involvement. As cervical myelopathy progresses due to increased severity of spinal cord compression, patients may complain of gait impairment and balance abnormalities, and bladder or bowel dysfunction as well [23].

Patients having DCM usually present with hand numbness, loss of fine motor function, bilateral paresthesia, impaired gait, lower extremity weakness, and incontinence or urgency of urination and defecation $[22,24]$. The physical examination of these patients reveals increased upper and lower extremity reflexes, lower extremity clonus, and positive Hoffman and Babinski signs [22,24,25]. Loss of sensation in the lower limbs involves both position and vibration sense, and pain and temperature sensation loss can occur on one side or both sides of the extremities. Spasticity causes gait abnormalities in the lower extremities and loss of dexterity in the upper extremities [22]. When single cervical radiculopathy coexists with myelopathy, a decrease in the deep tendon reflex of the upper extremity may be encountered [26]. In such cases, spinal cord compression at the C5-6 level may elicit an inverted brachioradialis reflex when the examiner taps the insertion site at the brachioradialis, causing paradoxical finger flexion $[26,27]$.

\section{Differential Diagnosis}

The differential diagnosis of DCM includes various diseases that can manifest as a cluster of myelopathic symptoms and signs. Some of these diseases are caused by intracranial, demyelinating, motor neuron, infectious, inflammatory, and metabolic abnormalities [28]. One such disease is amyotrophic lateral sclerosis (ALS), of which the symptoms include muscle weakness with muscle atrophy, fasciculations, and gait difficulty, usually due to weakness. Diminished reflex with or without the Babinski sign is also characteristic of ALS. Usually, magnetic resonance imaging (MRI) shows nonspecific findings and, occasionally, increased T2 signal intensity is noted in the posterior part of the bilateral internal capsule in the brain. Moreover, tongue fasciculation on physical examination and denervation patterns on electromyography are helpful in diagnosing ALS. Furthermore, cerebrospinal fluid 
study would show mild increase in albumin level and immunoglobulin $\mathrm{G}$ index and detectable oligoclonal bands.

Multiple sclerosis (MS) is a chronic autoimmune systemic disease that destroys myelin sheaths and axons in the central nervous system. The clinical course of MS is very diverse, usually with several episodes of reversible neurologic deficits, followed by progressive neurologic deterioration [28]. Initially, patients present with symptoms of paresthesia, dysesthesia, diplopia, urinary incontinence, and dizziness; however, as the disease progresses, paresthesia affects the pelvis, abdomen, or chest in an ascending pattern or shows unilateral leg numbness that spreads to the contralateral leg. Oligoclonal bands were detected in $>90 \%$ of patients with MS and an increased immunoglobulin G index was observed in $>60 \%$ of cerebrospinal fluid analyses [29].

Other conditions that can mimic the presentation of DCM include Parkinsonism, peripheral nerve entrapment, syringomyelia, primary spinal cord tumors, metastatic tumors, hereditary spastic paraplegia, subacute combined spinal cord degeneration caused by vitamin B12 deficiency, normal pressure hydrocephalus, and spinal cord infarction $[28,30]$.

\section{Diagnostic Tests}

Disk space narrowing, vertebral end plate sclerosis, osteophyte formation at the vertebral end plates, and hypertrophy in uncovertebral and facet joints are typical findings of a simple radiography in patients with cervical spondylosis. Oblique views are helpful in the diagnosis of foraminal stenosis due to uncinate process hypertrophy. The lateral view is essential for the confirmation of the extent of disk space narrowing, osteophyte formation at the vertebral end plates of the involved levels, and presence of spondylolisthesis or retrolisthesis. OPLL can be visualized as a bony bar posterior to the vertebral body or intervertebral disks. The cervical spine alignment should be elucidated because it may influence the selection of the surgical approach and the related modalities when surgical intervention is required.

In patients with symptoms and signs of myelopathy, MRI is a vital diagnostic tool. MRI can reveal the extent of pathologic changes in the intervertebral disk, hypertrophy or buckling of the ligamentum flavum, amount of decrease in spinal canal diameter, severity of spinal cord compression, and abnormal signal intensity of the intramedullary lesion. Several authors have reported a correlation between signal changes of the intramedullary lesion and the severity of myelopathy [31-34]. Despite the methodological variations in previous studies, both sharp and intense, and multisegmented T2-weighted increased signal intensity are associated with poor surgical outcomes. Postoperative regression of T2 signal intensity correlates with better functional outcomes [31-33]. Additionally, Suri et al. [34] revealed that in intramedullary lesions, decreased signal intensity on T1 and increased signal intensity on $\mathrm{T} 2$ resulted in poor surgical outcome for T2 changes alone. In patients with contraindications to MRI, computed tomography (CT) could be an effective diagnostic option. CT myelography in combination with MRI may be helpful in the diagnosis of bone abnormalities and spinal cord deformities; however, these modalities should be performed cautiously because of their invasive nature.

Electromyography and nerve conduction studies are useful in the identification of neural element injuries, such as carpal tunnel syndrome, ulnar cubital tunnel syndrome, or thoracic outlet syndrome, and the differential diagnosis of cervical myelopathy. The damage to the anterior horn cell or compression of the nerve root can manifest as increased insertional activity, fasciculations, and diminished motor unit recruitment on needle electromyography. Moreover, if the denervation is not fully restored, abnormal spontaneous activity, fibrillations, and positive sharp waves can occur [35]. Somatosensory evoked potentials, using the median and tibial nerves, can help to assess the degree of central sensory conduction delay or defects in patients with DCM [36]. Somatosensory and motor evoked potentials can be used intraoperatively. A preoperative baseline study can be very helpful, especially in patients with severe changes in latency and amplitude. Some authors advocate the use of intraoperative monitoring of the spinal cord through evoked potentials to observe the greatest level of conduction delay [37].

\section{Natural History}

In nonoperative patients, cervical myelopathy has a poor prognosis. Clarke and Robinson [38] reported the outcomes of 120 nonoperative patients who had cervical myelopathy; none of the patients experienced complete recovery. In the study, $75 \%$ of patients experienced episodic deterioration of neurologic status, $20 \%$ of patients 
had a slowly progressive neurologic status, and $5 \%$ of patients had a rapid onset of symptoms of myelopathy [38]. Furthermore, Roberts [39] reported the 6.5-year posttreatment experiences of 24 patients who underwent collar immobilization for the treatment of cervical myelopathy. According to the report, the condition of one-third of the patients improved, one-third did not experience any improvement from their pretreatment status, and the remaining one-third experienced deterioration with progressive worsening of their motor deficits, which were less likely to improve compared to their sensory deficits [39]. Additionally, patients who underwent conservative treatment tended to have a high risk of progressive neurologic deterioration and poor outcomes compared with those who underwent surgery. Generally, the conservative treatment is not recommended in patients with moderate, severe, or mild spinal stenosis. Moreover, the nonoperative treatment is not recommended in these patients because of the progressively worsening nature of cervical myelopathy [25].

\section{Operative Treatments}

Recently, a prospective multicenter study conducted by AO Spine North America revealed that the surgical decompression could not only prevent the progression of myelopathy but also improve neurologic status, functional outcomes, and quality of life, irrespective of differences in

Table 1. The modified Japanese Orthopaedic Association score

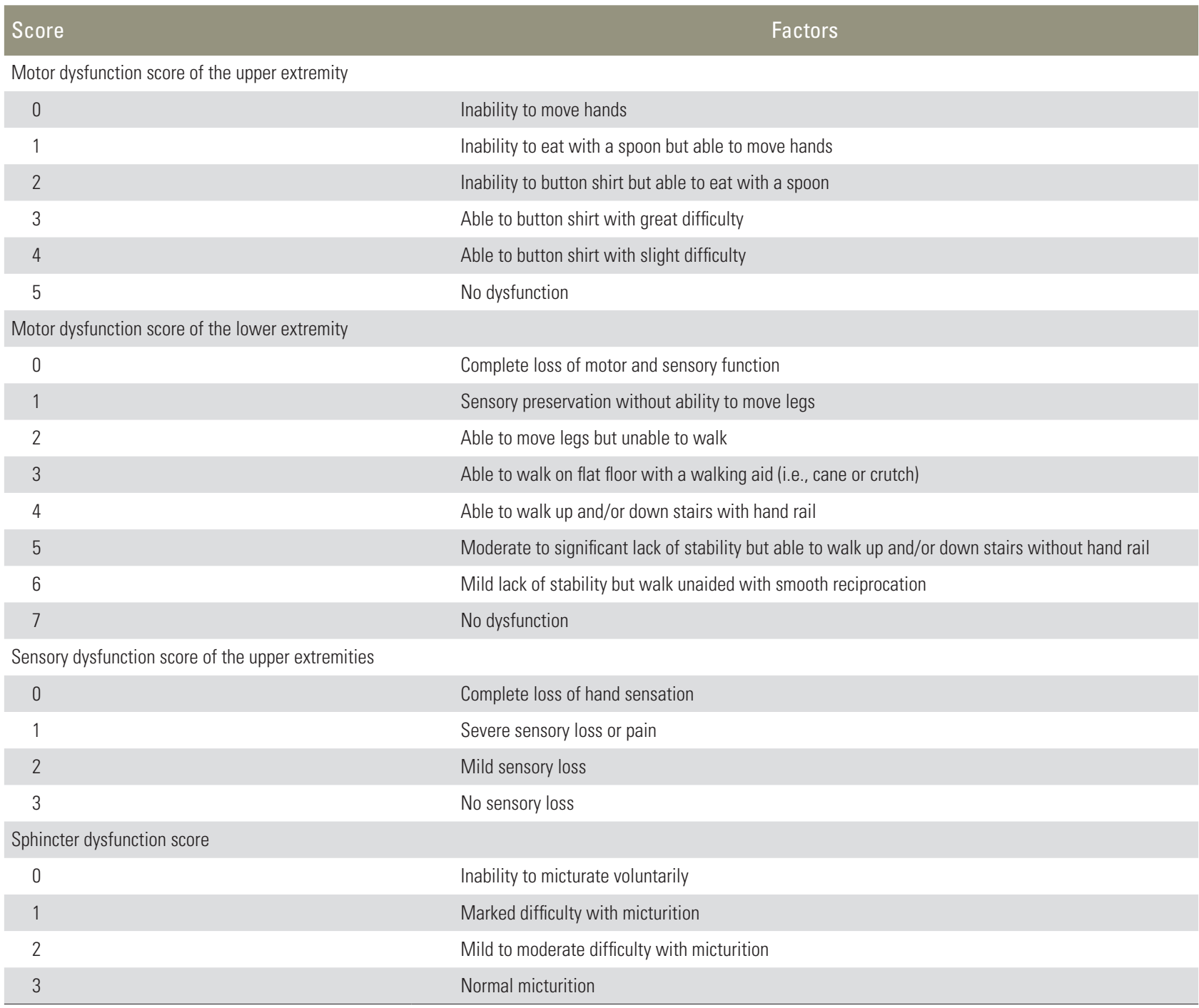


medical systems and sociocultural determinants of health $[40,41]$. In the study, $85.4 \%$ of patients who underwent surgical decompression procedures showed significant improvement in the modified Japanese Orthopaedic Association (JOA) score (Table 1), Nurick grade (Table 2), neck disability index score, and all 36-item Short Form Health Survey health dimensions during the 1-year follow-up [40].

Several factors, including disease etiology, anatomic structure that causes myelopathy, cervical alignment, coexisting neck pain, number of involved segments, and patient factors, should be considered while deciding the optimal surgical procedures for a patient. Generally, the anterior surgical approach is recommended for shortsegment soft or hard disk herniation, cervical spondylosis, and in cases where the underlying pathology of the cervical myelopathy is located anteriorly. It can also be selectively used in cases of severe cervical OPLL, using a technique named "vertebral body sliding osteotomy," for anterior decompression surgery where adhesion with the dura mater is expected [42]. The posterior surgical approach is mainly used in patients with multisegment spinal cord compression, such as in patients with cervical lordosis. However, it can also be used in some patients with neutral or cervical kyphosis. Furthermore, combined anterior-posterior fusions can be performed for effective spinal cord decompression in complicated cases of cervical spondylosis and OPLL having multisegment spinal cord compression along with kyphosis of the cervical spine.

\section{Anterior Surgery}

The anterior surgical approach to the cervical spine was introduced by Smith and Robinson and Cloward in the

Table 2. Nurick classification system for degenerative cervical myelopathy

\begin{tabular}{ll} 
Grade & \multicolumn{1}{c}{ Nurick classification system } \\
Grade 0 & No root or cord symptoms \\
Grade I & Roots signs or symptoms. No evidence of cord involvement \\
\hline Grade II & Signs of cord involvement. Normal gait \\
Grade III & Gait abnormality. Able to be employed \\
Grade IV & Gait abnormality prevents employment \\
Grade V & Able to ambulate only with assistance \\
Grade VI & Chair bound or bedridden \\
\hline
\end{tabular}

1950s. This approach is advantageous because it can remove or float the intervertebral disk, osteophytes, and OPLL that compress the spinal cord directly, by approaching the interfacial plane between the trachea, esophagus, and carotid sheath with the neck slightly extended in the supine position. Another advantage of anterior surgical approach is that it decompresses the main pathology without manipulating the spinal cord. After the decompression, arthroplasty or arthrodesis can be performed. The union rate of a single-level arthrodesis is reported to be $92 \%-96 \%$, and favorable long-term outcomes have been reported for cervical arthroplasty. During anterior arthrodesis, plate fixation was associated with significantly higher vertebral fusion rates (95\% confidence interval [CI], 1.16-3.37), lower subsidence rates ( $95 \%$ CI, 0.18-0.52), and more favorable scores in the Visual Analog Scale for neck pain [43]. For the decompression of the combined radiculopathy, additional unilateral or bilateral resection of the uncinate process during anterior cervical discectomy and fusion (ACDF) was reported to have not affected the fusion rate after single- or double-level ACDF [44]. For the decompression of multilevel spinal stenosis, various anterior decompressive surgical techniques have been introduced for multilevel ACDF, corpectomy, and hybrid surgery. Despite the favorable neurologic results of multilevel ACDF, the pseudarthrosis rate has been reported to increase in relation to that of the operated segment. The reported fusion rates for a two- and three-level ACDF decreased to $75 \%$ and $56 \%$, respectively, with increased number of graft-host sites for fusion $[43,45]$. Furthermore, several authors have reported that hybrid surgery with cervical arthroplasty and ACDF provided effective and safe treatment to patients with cervical myelopathy $[46,47]$.

Various recent studies have reported favorable longterm outcomes of cervical arthroplasty in single-level cervical degenerative disk disease. Despite the low-to-moderate quality of evidence, the visual analog scale scores for arm and neck pain and neck disability indices were significantly lower in patients at 3 months and 1-2 years after cervical disk replacement [48]. However, with the minimal differences in effect size and clinical relevance, the use of arthroplasty in cervical myelopathy is limited to the presence of soft disk herniation or minimally degenerative cervical spine [49].

Dysphagia, one of the commonest unintended sequelae of anterior surgery, is caused by the compression due to 
a self-retractor and the intratracheal pressure increase by the use of an intubation cuff during surgery. The incidence of esophageal perforation after anterior cervical spine surgery is very low, ranging from $0.2 \%$ to $0.9 \%$; however, postoperative dysphagia is relatively common, although it is frequently transient, ranging from $2 \%$ to $48 \%$ [50,51]. The causes of postoperative dysphagia are multifactorial and primarily due to hematoma formation after surgery, and the prolonged traction or direct pharyngeal plexus injury results in upper esophageal denervation. Permanent hoarseness occurs in $0.33 \%$ of cases, but temporary hoarseness occurs in $3 \%-11 \%$ of patients [52]. It has been reported that postoperative dysphonia commonly occurs in revision surgery and is highly associated with direct or indirect damage to the recurrent or superior laryngeal nerve. Ratnaraj et al. [53] reported that by lowering the endotracheal cuff pressure to $20 \mathrm{~mm} \mathrm{Hg}$, the swallowing difficulties after anterior cervical spine surgery could be significantly reduced. Additionally, airway obstruction due to edema or hematoma formation after anterior cervical spine surgery is a fatal complication. Several authors recommend that patients with severe myelopathy, upper cervical surgery, long operative time, and difficult airway should remain intubated postoperatively to prevent airway complications after surgery $[54,55]$.

\section{Posterior Surgery}

Patients who have DCM with multisegment pathology involving three or more levels can be expected to experience effective decompression using laminectomy, with or without concurrent posterior fusion, or laminoplasty through the posterior surgical approach. Posterior laminectomy was first introduced in 1901 as a surgical approach for patients with cervical spine fractures, and it has since been widely used for multilevel decompression of cervical spondylotic stenosis with satisfactory results [56]. However, some authors have reported that the aggravation of kyphosis and deterioration of neurologic symptoms due to scar formation around the dura mater may progress after posterior laminectomy. Moreover, segmental instability and kyphosis have also been reported as post-laminectomy syndromes [57]. Zdeblick and Ducker [58] reported that cervical instability occurs when $\geq 50 \%$ of facet joints are excised during foraminotomy. Nowinski et al. [59], through biomechanical studies, concluded that facetectomy of $>25 \%$ of facet joints may affect the stability of the cervical spine after multilevel laminectomy. Therefore, to prevent the iatrogenic instability and postlaminectomy kyphosis, some authors suggest prophylactic fusion after laminectomy [60,61]. There have been concerns regarding post-laminectomy kyphosis; hence, laminectomy with concurrent posterior fusion was introduced in the treatment of multilevel cervical myelopathy [60]. Currently, lateral mass screw fixation with bone grafts is the commonly applied procedure for rigid internal fixation, and high rates of fusion and functional recovery have been reported $[62,63]$. Some reported disadvantages of laminectomy and fusion include nonunion, hardware failure, adjacent segment degeneration, loss of lordosis, and discomfort in the autograft harvest site.

In Japan, to overcome the shortcomings of cervical fusion, a new laminoplasty technique that can achieve sufficient decompression of the spinal canal, while preserving the posterior facet joint, was introduced in 1973 [64]. Laminoplasty is classified into open-door laminoplasty, in which the spinal canal is expanded by creating singlesided hinge between the lamina and the facet joints, and double-door laminoplasty, in which hinges are created on both sides between the lamina and the facet joints by splitting the center of the spinous process [65]. Keyhole foraminotomy may also be performed to relieve the accompanied radiculopathy before expansion of the posterior arch (Fig. 2) [66]. In a study conducted on 80 patients who underwent open-door laminoplasty, Chiba et al. [67] observed that the average JOA score and recovery rate significantly improved for up to 3 years postoperatively and

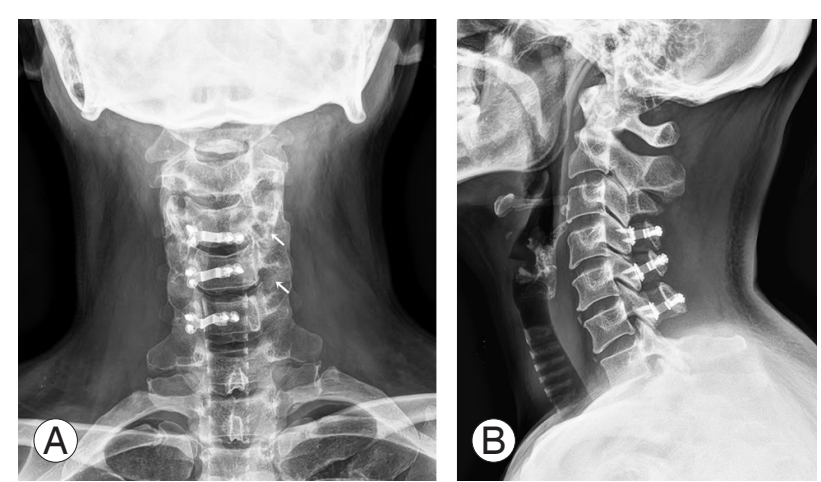

Fig. 2. A 51-year-old woman presents with loss of dexterity in both hands, gait difficulty, and radiating pain in the left upper limb. Posterior cervical laminoplasty was performed due to long-standing myeloradiculopathy. (A) Simple radiography 1 year after open-door laminoplasty with keyhole foraminotomy (white arrow). (B) Cervical lordosis and the posterior facet joint are preserved; thus, minimizing range of motion reduction in the cervical segment. 
slightly decreased at 5 years postoperatively, but an acceptable range was maintained subsequently. However, it was also noted that the loss of segmental range of motion, kyphosis and OPLL progression, and late deterioration after laminoplasty have not been resolved [67].

Major complications observed after posterior decompression surgery include an iatrogenic cord or root injury, C5 palsy, and late neurologic deterioration. Patients frequently complain of axial symptoms, such as neck pain, stiffness, and weakness or shoulder discomfort after posterior cervical procedures [68], and the underlying cause of these symptoms have not yet been established. It is known that when anterior cervical corpectomy and posterior multilevel decompression and fixation are performed simultaneously, more complications occur compared to those when other surgical methods are used $[68,69]$.

\section{Conclusions}

DCM presents with various degrees of symptoms and signs, and worsening myelopathy results in deterioration of the sensory or motor functions of the extremities. If compression of the spinal cord is confirmed on imaging tests in a patient with chronic cervical myelopathy, appropriate surgical treatment will not only suppress the disease progression but also improve the quality of life. The choice of surgical treatment should be based on the patient's general condition, extent of compression, presence of concomitant cervical radiculopathy, and cervical alignment. Understanding the pathophysiology of cervical myelopathy and improving the surgical techniques are expected to improve the prognosis in patients with DCM.

\section{Conflict of Interest}

No potential conflict of interest relevant to this article was reported.

\section{Acknowledgments}

This work was supported by the National Research Foundation of Korea (NRF) grant funded by the Korean government (MSIT) (No., 2018R1D1A1B07051146).

\section{References}

1. Fehlings MG, Skaf G. A review of the pathophysi- ology of cervical spondylotic myelopathy with insights for potential novel mechanisms drawn from traumatic spinal cord injury. Spine (Phila Pa 1976) 1998;23:2730-7.

2. Nouri A, Tetreault L, Singh A, Karadimas SK, Fehlings MG. Degenerative cervical myelopathy: epidemiology, genetics, and pathogenesis. Spine (Phila $\mathrm{Pa}$ 1976) 2015;40:E675-93.

3. Sekhon LH, Fehlings MG. Epidemiology, demographics, and pathophysiology of acute spinal cord injury. Spine (Phila Pa 1976) 2001;26(24 Suppl):S2-12.

4. Murone I. The importance of the sagittal diameters of the cervical spinal canal in relation to spondylosis and myelopathy. J Bone Joint Surg Br 1974;56:30-6.

5. Arnold JG Jr. The clinical manifestations of spondylochondrosis (spondylosis) of the cervical spine. Ann Surg 1955;141:872-89.

6. Boijsen E. The cervical spinal canal in intraspinal expansive processes. Acta radiol 1954;42:101-15.

7. Pavlov H, Torg JS, Robie B, Jahre C. Cervical spinal stenosis: determination with vertebral body ratio method. Radiology 1987;164:771-5.

8. Bernhardt M, Hynes RA, Blume HW, White AA 3rd. Cervical spondylotic myelopathy. J Bone Joint Surg Am 1993;75:119-28.

9. Parke WW. Correlative anatomy of cervical spondylotic myelopathy. Spine (Phila Pa 1976) 1988;13:8317.

10. Rao R. Neck pain, cervical radiculopathy, and cervical myelopathy: pathophysiology, natural history, and clinical evaluation. J Bone Joint Surg Am 2002;84:1872-81.

11. White AA, Southwick WO, Panjabi MM. Clinical instability in the lower cervical spine a review of past and current concepts. Spine 1976;1:15-27.

12. Henderson FC, Geddes JF, Vaccaro AR, Woodard E, Berry KJ, Benzel EC. Stretch-associated injury in cervical spondylotic myelopathy: new concept and review. Neurosurgery 2005;56:1101-13.

13. Scheer JK, Tang JA, Smith JS, et al. Cervical spine alignment, sagittal deformity, and clinical implications: a review. J Neurosurg Spine 2013;19:141-59.

14. Shi R, Pryor JD. Pathological changes of isolated spinal cord axons in response to mechanical stretch. Neuroscience 2002;110:765-77.

15. Karadimas SK, Gatzounis G, Fehlings MG. Pathobiology of cervical spondylotic myelopathy. Eur Spine J 
2015;24 Suppl 2:132-8.

16. Vidal PM, Karadimas SK, Ulndreaj A, et al. Delayed decompression exacerbates ischemia-reperfusion injury in cervical compressive myelopathy. JCI Insight 2017;2:e92512.

17. Park E, Velumian AA, Fehlings MG. The role of excitotoxicity in secondary mechanisms of spinal cord injury: a review with an emphasis on the implications for white matter degeneration. J Neurotrauma 2004;21:754-74.

18. Gooding MR, Wilson CB, Hoff JT. Experimental cervical myelopathy: autoradiographic studies of spinal cord blood flow patterns. Surg Neurol 1976;5:233-9.

19. Baptiste DC, Fehlings MG. Pathophysiology of cervical myelopathy. Spine J 2006;6(6 Suppl):190S-197S.

20. Crowe MJ, Bresnahan JC, Shuman SL, Masters JN, Beattie MS. Apoptosis and delayed degeneration after spinal cord injury in rats and monkeys. Nat Med 1997;3:73-6.

21. Kim DH, Vaccaro AR, Henderson FC, Benzel EC. Molecular biology of cervical myelopathy and spinal cord injury: role of oligodendrocyte apoptosis. Spine J 2003;3:510-9.

22. Tracy JA, Bartleson JD. Cervical spondylotic myelopathy. Neurologist 2010;16:176-87.

23. Harrop JS, Naroji S, Maltenfort M, et al. Cervical myelopathy: a clinical and radiographic evaluation and correlation to cervical spondylotic myelopathy. Spine (Phila Pa 1976) 2010;35:620-4.

24. Kalsi-Ryan S, Karadimas SK, Fehlings MG. Cervical spondylotic myelopathy: the clinical phenomenon and the current pathobiology of an increasingly prevalent and devastating disorder. Neuroscientist 2013;19:409-21.

25. Badhiwala JH, Wilson JR. The natural history of degenerative cervical myelopathy. Neurosurg Clin N Am 2018;29:21-32.

26. Luo W, Li Y, Xu Q, Gu R, Zhao J. Cervical spondylotic amyotrophy: a systematic review. Eur Spine J 2019;28:2293-301.

27. Ebara S, Yonenobu K, Fujiwara K, Yamashita K, Ono K. Myelopathy hand characterized by muscle wasting: a different type of myelopathy hand in patients with cervical spondylosis. Spine (Phila Pa 1976) 1988;13:785-91.

28. Kim HJ, Tetreault LA, Massicotte EM, et al. Differential diagnosis for cervical spondylotic myelopathy: literature review. Spine (Phila Pa 1976) 2013;38(22 Suppl 1):S78-88.

29. Kouri A, Tanios M, Herron JS, Cooper M, Khan M. Mimickers of cervical spondylotic myelopathy. JBJS Rev 2018;6:e9.

30. Nouri A, Patel K, Montejo J, et al. The role of vitamin $\mathrm{B} 12$ in the management and optimization of treatment in patients with degenerative cervical myelopathy. Global Spine J 2019;9:331-7.

31. Vedantam A, Rajshekhar V. Does the type of T2weighted hyperintensity influence surgical outcome in patients with cervical spondylotic myelopathy?: a review. Eur Spine J 2013;22:96-106.

32. Matsumoto M, Toyama Y, Ishikawa M, Chiba K, Suzuki N, Fujimura Y. Increased signal intensity of the spinal cord on magnetic resonance images in cervical compressive myelopathy: does it predict the outcome of conservative treatment? Spine (Phila Pa 1976) 2000;25:677-82.

33. Yukawa Y, Kato F, Yoshihara H, Yanase M, Ito K. MR T2 image classification in cervical compression myelopathy: predictor of surgical outcomes. Spine (Phila Pa 1976) 2007;32:1675-8.

34. Suri A, Chabbra RP, Mehta VS, Gaikwad S, Pandey RM. Effect of intramedullary signal changes on the surgical outcome of patients with cervical spondylotic myelopathy. Spine J 2003;3:33-45.

35. Dvorak J, Sutter M, Herdmann J. Cervical myelopathy: clinical and neurophysiological evaluation. Eur Spine J 2003;12 Suppl 2(Suppl 2):S181-7.

36. Nakai S, Sonoo M, Shimizu T. Somatosensory evoked potentials (SEPs) for the evaluation of cervical spondylotic myelopathy: utility of the onset-latency parameters. Clin Neurophysiol 2008;119:2396-404.

37. Emery SE. Cervical spondylotic myelopathy: diagnosis and treatment. J Am Acad Orthop Surg 2001;9:376-88.

38. Clarke E, Robinson PK. Cervical myelopathy: a complication of cervical spondylosis. Brain 1956;79:483510.

39. Roberts AH. Myelopathy due to cervical spondylosis treated by collar immobilization. Neurology 1966;16:951.

40. Fehlings MG, Wilson JR, Kopjar B, et al. Efficacy and safety of surgical decompression in patients with cervical spondylotic myelopathy: results of the AOSpine North America prospective multi-center study. J 
Bone Joint Surg Am 2013;95:1651-8.

41. Fehlings MG, Ibrahim A, Tetreault L, et al. A global perspective on the outcomes of surgical decompression in patients with cervical spondylotic myelopathy: results from the prospective multicenter AOSpine international study on 479 patients. Spine (Phila Pa 1976) 2015;40:1322-8.

42. Lee DH, Cho JH, Lee CS, Hwang CJ, Choi SH, Hong CG. A novel anterior decompression technique (vertebral body sliding osteotomy) for ossification of posterior longitudinal ligament of the cervical spine. Spine J 2018;18:1099-105.

43. Oliver JD, Goncalves S, Kerezoudis P, et al. Comparison of outcomes for anterior cervical discectomy and fusion with and without anterior plate fixation: a systematic review and meta-analysis. Spine (Phila $\mathrm{Pa}$ 1976) 2018;43:E413-22.

44. Lee DH, Cho JH, Baik JM, et al. Does additional uncinate resection increase pseudarthrosis following anterior cervical discectomy and fusion? Spine (Phila Pa 1976) 2018;43:97-104.

45. Wang JC, McDonough PW, Endow KK, Delamarter $\mathrm{RB}$. Increased fusion rates with cervical plating for two-level anterior cervical discectomy and fusion. Spine (Phila Pa 1976) 2000;25:41-5.

46. Ashkenazi E, Smorgick Y, Rand N, Millgram MA, Mirovsky Y, Floman Y. Anterior decompression combined with corpectomies and discectomies in the management of multilevel cervical myelopathy: a hybrid decompression and fixation technique. J Neurosurg Spine 2005;3:205-9.

47. Chen J, Xu L, Jia YS, et al. Cervical anterior hybrid technique with bi-level Bryan artificial disc replacement and adjacent segment fusion for cervical myelopathy over three consecutive segments. J Clin Neurosci 2016;27:59-62.

48. Boselie TF, Willems PC, van Mameren $\mathrm{H}$, de Bie RA, Benzel EC, van Santbrink H. Arthroplasty versus fusion in single-level cervical degenerative disc disease: a Cochrane review. Spine (Phila Pa 1976) 2013;38:E1096-107.

49. Jain NS, Nguyen A, Formanek B, et al. Cervical disc replacement: trends, costs, and complications. Asian Spine J 2020 Mar 30 [Epub]. https://doi. org/10.31616/asj.2019.0246.

50. Ko SB, Park JB, Song KJ, et al. Esophageal perforation after anterior cervical spine surgery. Asian Spine
J 2019;13:976-83.

51. Joaquim AF, Murar J, Savage JW, Patel AA. Dysphagia after anterior cervical spine surgery: a systematic review of potential preventative measures. Spine J 2014;14:2246-60.

52. Zhu B, Xu Y, Liu X, Liu Z, Dang G. Anterior approach versus posterior approach for the treatment of multilevel cervical spondylotic myelopathy: a systemic review and meta-analysis. Eur Spine J 2013;22:1583-93.

53. Ratnaraj J, Todorov A, McHugh T, Cheng MA, Lauryssen C. Effects of decreasing endotracheal tube cuff pressures during neck retraction for anterior cervical spine surgery. J Neurosurg 2002;97(2 Suppl):176-9.

54. Emery SE, Akhavan S, Miller P, et al. Steroids and risk factors for airway compromise in multilevel cervical corpectomy patients: a prospective, randomized, double-blind study. Spine (Phila Pa 1976) 2009;34:229-32.

55. Emery SE, Smith MD, Bohlman HH. Upper-airway obstruction after multilevel cervical corpectomy for myelopathy. J Bone Joint Surg Am 1991;73:544-51.

56. Edwards CC 2nd, Riew KD, Anderson PA, Hilibrand AS, Vaccaro AF. Cervical myelopathy. current diagnostic and treatment strategies. Spine J 2003;3:68-81.

57. Heller JG, Edwards CC 2nd, Murakami H, Rodts GE. Laminoplasty versus laminectomy and fusion for multilevel cervical myelopathy: an independent matched cohort analysis. Spine (Phila Pa 1976) 2001;26:1330-6.

58. Zdeblick TA, Ducker TB. The use of freeze-dried allograft bone for anterior cervical fusions. Spine (Phila Pa 1976) 1991;16:726-9.

59. Nowinski GP, Visarius H, Nolte LP, Herkowitz HN. A biomechanical comparison of cervical laminaplasty and cervical laminectomy with progressive facetectomy. Spine (Phila Pa 1976) 1993;18:1995-2004.

60. Kumar VG, Rea GL, Mervis LJ, McGregor JM. Cervical spondylotic myelopathy: functional and radiographic long-term outcome after laminectomy and posterior fusion. Neurosurgery 1999;44:771-7.

61. Epstein NE. Laminectomy with posterior wiring and fusion for cervical ossification of the posterior longitudinal ligament, spondylosis, ossification of the yellow ligament, stenosis, and instability: a study of 5 patients. J Spinal Disord 1999;12:461-6.

62. Du W, Zhang P, Shen Y, Zhang YZ, Ding WY, Ren LX. Enlarged laminectomy and lateral mass screw 
fixation for multilevel cervical degenerative myelopathy associated with kyphosis. Spine J 2014;14:57-64.

63. Lau D, Winkler EA, Than KD, Chou D, Mummaneni PV. Laminoplasty versus laminectomy with posterior spinal fusion for multilevel cervical spondylotic myelopathy: influence of cervical alignment on outcomes. J Neurosurg Spine 2017;27:508-17.

64. Satomi K, Nishu Y, Kohno T, Hirabayashi K. Longterm follow-up studies of open-door expansive laminoplasty for cervical stenotic myelopathy. Spine (Phila Pa 1976) 1994;19:507-10.

65. Hirabayashi K, Watanabe K, Wakano K, Suzuki N, Satomi K, Ishii Y. Expansive open-door laminoplasty for cervical spinal stenotic myelopathy. Spine (Phila Pa 1976) 1983;8:693-9.
66. Lee DH, Cho JH, Hwang CJ, Lee CS, Kim C, Ha JK. Multilevel posterior foraminotomy with laminoplasty versus laminoplasty alone for cervical spondylotic myelopathy with radiculopathy: a comparative study. Spine J 2018;18:414-21.

67. Chiba K, Ogawa Y, Ishii K, et al. Long-term results of expansive open-door laminoplasty for cervical myelopathy: average 14-year follow-up study. Spine (Phila Pa 1976) 2006;31:2998-3005.

68. Rhee JM, Basra S. Posterior surgery for cervical myelopathy: laminectomy, laminectomy with fusion, and laminoplasty. Asian Spine J 2008;2:114-26.

69. Sugawara T. Neurologic complications in managing degenerative cervical myelopathy: pathogenesis, prevention, and management. Neurosurg Clin N Am 2018;29:129-37. 